\title{
Sistem Kendali Suhu Dan Kelembaban Pada Greenhouse Tanaman Sawi Berbasis IoT
}

\author{
Agus Maulana Khafi ${ }^{1}$, Danang Erwanto ${ }^{2}$, Yudo Bismo Utomo ${ }^{3}$ \\ 1,2,3 Teknik Elektro, Fakultas Teknik, Universitas Islam Kadiri Kediri \\ E-mail: *1Khafi93@yahoo.com, ${ }^{2}$ Danangerwanto@uniska-kadiri.ac.id, \\ 3Yudobismo@uniska-kadiri.ac.id
}

\begin{abstract}
Abstrak - Tanaman sawi adalah tanaman yang membutuhkan pemeliharaan yang rumit. Pada musim kemarau tanaman sawi dapat tumbuh dengan baik tetapi harganya murah sedangkan pada musim penghujan tanaman sawi tidak bisa tumbuh dengan baik karena terlalu banyak kandungan kadar airnya tetapi pada musim tersebut harga sawi tinggi, untuk mengatasi hal tersebut petani membudidayakan tanaman sawi pada Greenhouse agar tanaman sawi tidak terpengaruh cuaca diluar ruangan. Tetapi kendalanya Suhu dan kelembaban pada greenhouse terlalu rendah sehingga pengap dan tanaman sawi kering. Untuk mengantisipasi hal tersebut petani membuat alat untuk mengendalikan suhu dan kelembaban pada greenhouse agar suhu dan kelembaban tetap stabil, dengan penggunaan sensor DHT11 untuk mendeteksi suhu dan kelembaban udara serta sensor YL 100 untuk mendeteksi kelembaban tanah dengan alat pengendali yang digunakan adalah Arduino Uno, untuk mempermudah kerja petani dalam membudidayakan tanaman sawi petani memadukan alat tersebut dengan teknologi terbarukan yaitu internet of things agar petani dapat memantau dan melakukan tindakan penyesuaian suhu dan kelembaban pada greenhouse melalui Android.
\end{abstract}

Kata Kunci - Sawi, Greenhouse, Arduino, DHT11, YL-100, IoT.

Abstract - Mustard plants are plants that require complex maintenance. In the dry season mustard plants can grow well but the price is cheap while in the rainy season the mustard plants cannot grow well because of too much water content but in that season the price of mustard plant is high, to overcome this the farmers cultivate mustard plants on the greenhouse so that mustard plants will not affected by weather outside the room. But the problem is that the temperature and humidity in the greenhouse is too low so that it is stuffy and the mustard plants is dry. To anticipate this, the farmers make a tool to control temperature and humidity in the greenhouse so that temperature and humidity remain stable, using the DHT11 sensor to detect air temperature and humidity as well as YL 100 sensors to detect soil moisture with the Arduino Uno controller. the work of farmers in cultivating mustard farmers combines these tools with renewable technology, namely the internet of things so farmers can monitor and take measures to adjust temperature and humidity in the greenhouse via Android

Keywords - Mustard, Greenhouse, Arduino, DHT11, YL-100, IoT

\section{PENDAHULUAN}

Tanaman sawi merupakan tanaman yang tergolong subur apabila kondisi tanah yang lembab dan tingkat kebutuhan air yang tepat. tanah yang lembab membantu pertumbuhan menjadi lebih maksimal hasil produksi sawi lebih subur dan pertumbuhan cepat. Penanaman sawi yang langsung diladang tanpa greenhouse sering terganggu cuaca buruk. cuaca penghujan dan cuaca kemarau sehinggah tingkat produksi tanaman terganggu. Penelitian ini menggunakan greenhouse untuk memanipulasi suhu dan kelembaban yang di butuhkan oleh tanaman dengan beberapa herdwer dan softwere untuk memaksimalkan kelembaban udara dan kelembaban tanah untuk tanaman sawi didalam greenhouse. Penelitian ini hampirsama dengan penelitian yang sebelumnya hanya saja penelitian ini menggunakan IOT untuk penempilan nilai yang dihasilkan oleh kedua. sensor DHT11 dan sensor soil masture YL100. Agar pemantauan kondisi didalam greenhouse lebih mudah dipantau 
tanpa harus datang didalam greenhouse tersebut. Sedangkan yang dulu hanya menggunakan LCD untuk menampilkan nilai sensor DHT11 dan tidak memakai sensor soil moisture YL100. Tanaman yang digunakan pada penelitian ini yaitu tanaman sawi sedangkan yang dulu kedelai hanya saja tanaman sawi masa pemanenannya 30 hari sangat cepat dari kedelai. Untuk mengkondisikan kelembaban udara dan kelembaban tanah pada greenhouse. Penelitian ini menggunakan pompa air AC dan sprayer serta kipas AC untuk memanipulasi air seperti empun agar tanaman tidak rusak pada batang sawi. Sedangkan untuk penelitian yang sebelunnya menggunakan peltier untuk memanipulasi kelembaban udara dan pompa air DC untuk kelembaban tanah didalam greenhouse.

\section{METODE PENELITIAN}

\subsection{Greenhouse}

Greenhouse merupakan plant dari proyek akhir ini merupakan salah satu bangunan yang dapat digunakan untuk melakukan budidaya tanaman di dalam ruangan. bangunan ini mempunyai atap yang terbuat dari kaca atau bisa diganti dengan plastik yang bening. Dia menjadi panas karena radiasi elektromagnetik yang di pancarkan matahari. Rumah kaca dapat berfungsi untuk menangkap energi panas matahari yang dipancarkan sehingga energi panas tetap berada di dalam bangunan greenhouse tersebut sehingga dapat memanaskan udara dekat tanah dan udara dicegah naik ke atas dan mengalir keluar. Karena itu greenhouse dapat menangkap radiasi elektromagnetik dan mencegah konversi.[1]

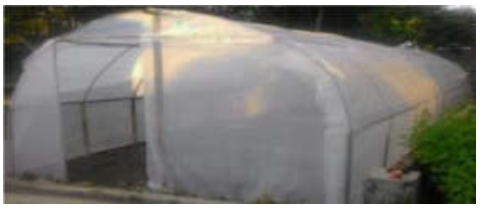

Gambar 1. greenhouse

\subsection{Tanaman sawi}

Tanaman sawi merupakan salah satu tanaman semusim yang tergolong subur terhadap kondisi kelembapan tanah yang baik. Penentuan tingkat kebutuhan air yang tepat sangan membantu untuk meningkatkan produksi tanaman sawi.

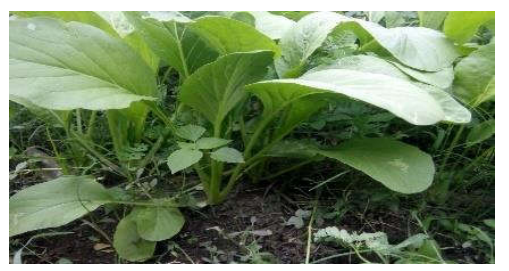

Gambar 2. Tanaman Sawi

Tanaman sawi juga merupakan tanaman yang berakar serabut. Pada akar tersebut hanya berakar pada permukaan tanah dengan kedalaman $5 \mathrm{~cm}$ dan tidak memeilikai akar tunggal. Pada tanaman tersebut bisa tumbuh baik pada tanah yang gembur dan subur dengan penyerapan air yang mudah dan dalam. [2]. Syarat tumbuh tanaman sawi adalah sebagai berikut :

\subsubsection{Iklim}

Daerah yang cocok pada penanaman sawi dengan ketinggian 5 meter sampai 1.200 meter dpl namun di indonesia sawi ditanam pada ketinggian 100500 meter dpl dengan ketinggian tersebut dan syarat syarat tersebut sudah memenuhi Kondisi iklim yang buruk sangat berpengaruh bagi pertumbuhan tanaman tersebut iklim yang cocok pada tanaman sawi yang mempunyai suhu malam $15.6^{\circ} \mathrm{C}$ sedangkan untuk suhu siang $21.1^{\circ} \mathrm{C}$ serta penyinaran matahari yang mencapai $12-16$ jam perhari .[2] 


\subsubsection{Tanah}

Tanah yang cocok bagi tanaman sawi adalah tanah yang gembur mengandung humus serta kemasan ph yang optimal di antara ph 6 - ph 7. Sawi juga dapat ditaman pada berbagai tanah namaun akan bagusnya pada tanah lempung berpasir serta andosol [3].

\subsection{Pengertian internet of things}

Internet of things merupakan sebuah penggabungan kata dari internet dan things arti sebuah kata dari internet adalah sebuah jaringan komputer yang menggunakan jaringan protokol dan arti kata things dapat diartikan sebagai objek fisik. Objek objek tersebut misal sensor data yang terbaca oleh sensor dapat dikirim melalui internet. Dari data pembacaan sensor yang sudah dikirim melalui internet maka memerlukan sebuah penyajian yang dapat dimengerti oleh pengguna agar dapat mempermudah modul pertukaran informasi Antara Bahasa analod sensor dengan Bahasa digital server atau aplikasi yang dapat dipahami oleh pengguna aplikasi [4].

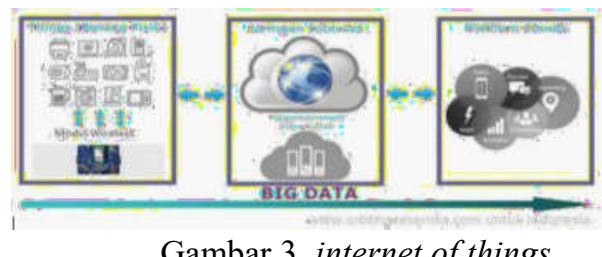

Gambar 3. internet of things

\subsection{Pengertian modul ESP8266}

Modul ESP8266 merupakan sebuah chip yang digunakan sebagai pengiriman data dari sebuah microkontroler menuju sebuah komputer server dengan menggunakan media wireless. Modul tersebut juga meyediakan akses jaringan wi-fi secara transparan dengan menggunakan interkoneksi serial ( UART. RX. TX ). Pada modul ESP8266 juga sudah dilengkapi dengan mikrokontroler RISC (tensicial $106_{u}$ diamond standard core LX3). Dan flash memory SPI 4 mbit winbond W2540BVNIG terpadu.[5]

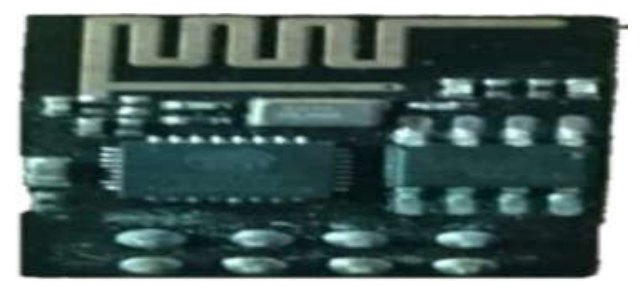

Gambar 4. modul ESP8266

\subsection{Arduino uno}

Arduino Uno sebuah bord mikrokontreler berbasis AT mega 328. Arti uno sendiri yang memiliki 14 pin digital input dan otput .yang dimana 6 pin dapat digunakan sebagai otput PWM dan 6 pin analog resonator keramik $1616 \mathrm{MHz}$, koneksi USB, jack listrik, header ICSP, dan tombol reset. Uno dibangun berdasarkan apa yang diperlukan untuk mendukung mikrokontroler, sumber daya bisa menggunakan power USB (jika terhubung ke komputer dengan kabel USB) dan juga dengan adaptor atau baterai [6]

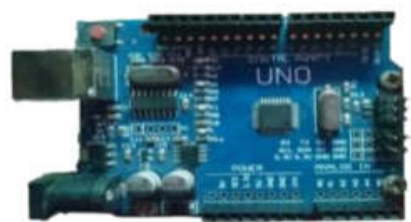

Gambar 5. Arduino uno 


\subsection{Sensor kelembapan tanah YL 100}

Sensor YL 100 merupakan sensor yang mendeteksi inteksitas air dalam tanah. Sensor ini sangat ideal untuk memantau tingkat kadar air pada tanaman. sensor ini terdiri dari dua probe untuk melewati arus melalui tanah. Kemudian membaca resistensi untuk mendapatkan nilai tingkat kelembaban. semakin tanah lembab akan semakin mudah untuk menghantarkan listrik. (resistensi kecil) sedangkan untuk tanah yang kering sangat sulit untuk menghantarkan listrik (resistensi besar) berikut ini gambar sensor YL 100 .

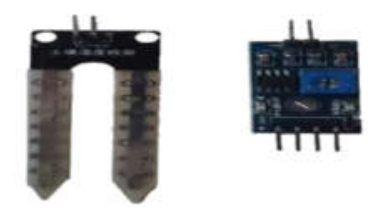

Gambar 6. Sensor Soil Moisture YL 100

1. Pin VCC di hubungkan ke $5 \mathrm{~V}$ pada arduino uno

2. Pin AO di hubungkan ke pin AO pada arduino uno

3. Pin DO di hubungkan ke pin 12 pada arduino uno

4. Pin GRN dihubungkan ke pin GND pada arduino uno [7]

\subsection{Sensor DHT 11}

Sebuah single chip sensor suhu dan kelembaban yang otput ya dikalibrasikan secara digital bagian dalam sensor ini terdapat elemen polimer untuk kelembaban relatif dan sebuah pita regangan yang digunakan sebagai Temperatur. Otput kedua sensor tersebut digabungkan dengan ADC 14 bit.

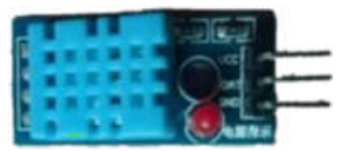

Gambar 7. Sensor Suhu Dan Kelembaban Udara DHT11

1) VCC dihubungkan ke sumber tegangan $5 \mathrm{~V}$

2) DATA dihubungkan ke pin analog

3) GND dihubungkan ke ground. [8]

\section{HASIL DAN PEMBAHASAN}

\subsection{Rancangan Alat}

Rancangan alat ini terdiri dari tiga macam. Yaitu rancang alat secara mekanik. Hardware dan sofware.

Mekanik Kerangka Greenhouse dibutuhkan ukuran sebagai berikut :

1) Bahan

2) Ukuran

- $\quad$ Besi untuk kerangka.

- $\quad$ Plasti dan paranet untuk penutup.

- $\quad$ Panjang $=6$ Meter

- Lebar $=4$ Meter

- $\quad$ Tinggi $=5$ Meter 


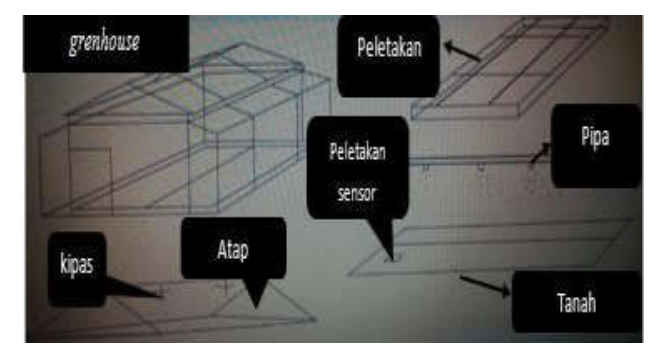

Gambar 8. Kerangka Greenhouse

Gambar diatas merupakan kerangka greenhouse yang nantinya akan dibangun untuk penelitian dan pengujuan alat. Dalam greenhouse tersebut terdapat sprayer. Peletakan prayer terdapat pada sisi atas begitu juga dengan kipas juga yang akan diletakan diatas sprayer. Dalam peletakan sensor soil moisture akan diletakan dibawah dan dilengkapi pelindung agar tidak rusak ketika terkena air jika sprayer menyala. Sensor DHT11 akan dikasih pelindung agar tidak terkena semprotan sprayer apabila sprayer menyala. Karena sensor DHT11 hampir dekat disebelah sprayer.

\subsection{Hardware}

Skema rangkaian

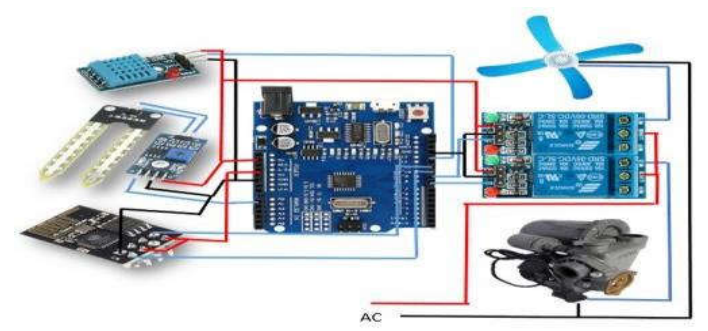

Gambar 9. Rangkaian alat

Gambar diatas merupakan pemasangan sensor soil moisture YL100 dan DHT11. Penggunaan Arduino uno di tunjukan sebagai proses data input relay sebagai control aktuator. Pemasangan chip esp8266 sebagai modul pengirim data dari Arduino uno dengan server yang menggunakan jaringan internet sebagai akses data tersebut.

\subsection{Logika Alat}

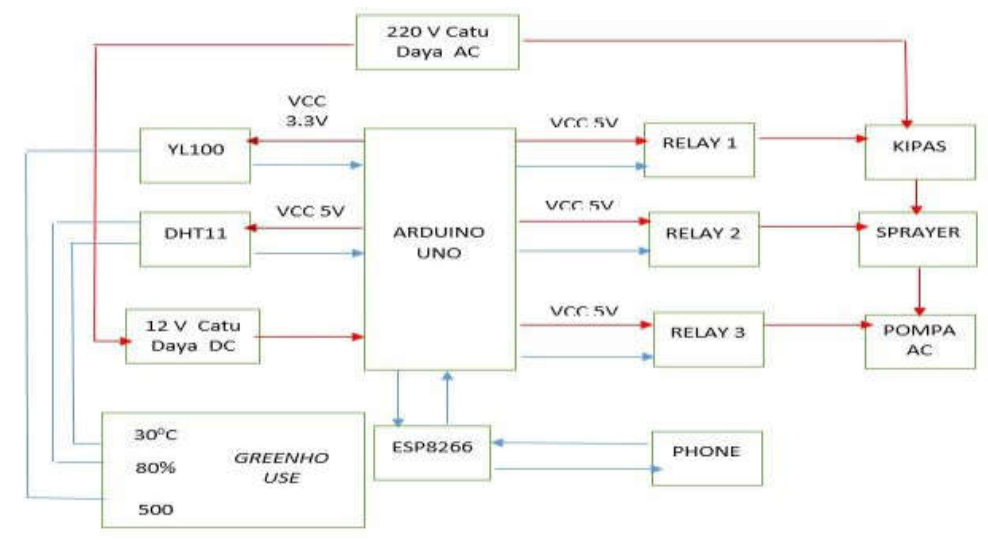

Gambar 10. logika alat 
Sensor dapat membaca data apabila diberi tegangan 5V pada pin VCC sensor. Output dari sensor tersebut disambungkan pada pin data Arduino Uno. Data yang diterima Arduino Uno dari output sensor berupa data ADC yang akan diubah menjadi data digital yang akan dimasukan pada serial monitor dengan data pembacaan input sensor tersebut. Alat mampu bekerja apabila bembacaan dari kedua sensor tidak sesuai oleh data yang sudah di masukan pada program IDE Arduino. Relay 1 dan Relay 2 mampu bekerja apabila arduino mendapatkan data nilai pembacaan sensor DHT11 apa bila suhu lebih dari $30^{\circ} \mathrm{c}$ dan kelembaban udara kurang dari 80\% makan relay 1 dan relay 2 menyala untuk menghidupkan kipas dan sprayer. Relay 3 mampu bekerja apabila arduino mambaca data output sensor YL100 apabila kadar air kurang dari kelembaban tanah 500 makan pompa air menyala. Hasil pembacaan data sensor yang sudah diterima oleh Arduino Uno data data tersebut dikirimka pada sematphone dan hasih pembacaan sensor tersebut apa pada sematphon dengan aplikasi yang sudah disediakan. Pengiriman data terset di kirim melalui jaringan internet dengan bantuan chip ESP8266 yang sudah di koneksikan pada Arduino Uno tersebut

\subsection{FLOWCHART}

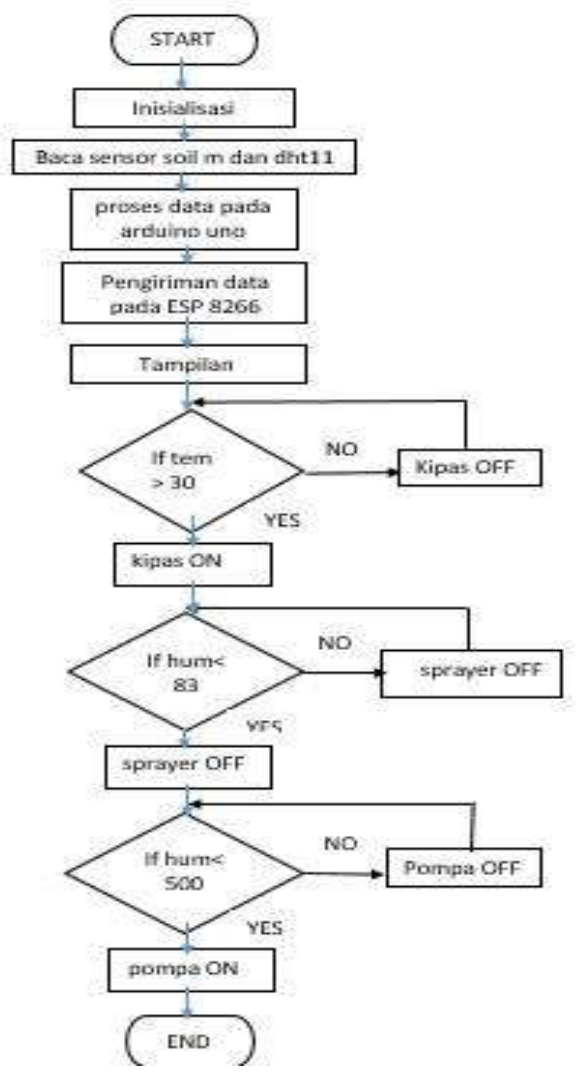

Gambar 11. logika alat

Pembacaan Program Sofware akan berlangsung Otomatis ketika Tombol Start ditekan kemudian Inisialisasi Aktuator berjalan dan pembacaan Sensor Soil Moistur dan Sensor DHT11 berlangsung dengan tombol Stat di tekan. Pada pembacaan Sensor tersebut akan di Proses dan di Inisialisasi pada ARDUINO UNO. Dalam Proses tersebut Data yang dapat di baca Sensor di kirim menggunakan Modul ESP 8266 Modul tersebut mengirim Data melalu Jaringan Internet sebagai Akses penghubung antara ARDUINO UNO dan pengguna.Dalam proses tersebut ARDUINO UNO akan mengontro jika Sensor DHT11 membaca suhu dengan nilai $>30$ c makan kipas akan menyala dengan Otomatis. Jika nilai kelembaban $<83 \%$ makan Sprayer akan ON. Pembacaan sensor soil moistur yang mampu membaca tingkat kelembaban tanah yang >500 makan pompa air ON dengan Otomatis. 


\subsection{Tampilan pada aplikasi Blink}

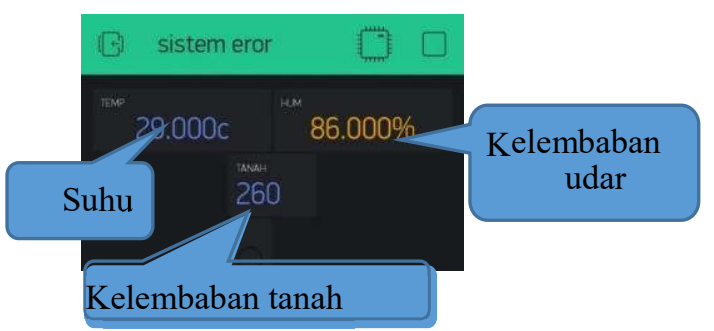

Gambar 12. tampilan pada aplikasi blink

3.6 Hasil Pengujian Alat secara otomatis

Pengujian otomatis yang di hasilkan sensor dengan pemanfaatan kipas dan Sprayer serta pompa air otomatis. berikut ini adalah tabel pengukuran dari Sensor DHT11 dan soil moisture YL100.

Tabel 1. suhu dan kelembaban awal sensor DHT11 dan YL100

Tabel di atas

\begin{tabular}{|c|c|c|c|c|}
\hline HARI & JAM & Suhu & Kelembaban udara & Kelembaban tanah \\
\hline Senin & 07.30 & $25^{\circ} \mathrm{c}$ & $85 . \%$ & 500 \\
\hline & 12.30 & $44^{\circ} \mathrm{c}$ & $29 . \%$ & 350 \\
\hline & 17.30 & $27^{\circ} \mathrm{c}$ & $81 . \%$ & 460 \\
\hline Selasa & 07.30 & $22^{\circ} \mathrm{c}$ & $90 . \%$ & 527 \\
\hline & 12.30 & $46^{\circ} \mathrm{c}$ & $27 . \%$ & 373 \\
\hline & 17.30 & $23^{\circ} \mathrm{c}$ & $93 . \%$ & 430 \\
\hline Rabo & 07.30 & $28^{\circ} \mathrm{c}$ & $76 . \%$ & 635 \\
\hline & 12.30 & $48^{\circ} \mathrm{c}$ & $20 . \%$ & 450 \\
\hline & 17.30 & $32^{\circ} \mathrm{c}$ & $89 . \%$ & 500 \\
\hline Kamis & 07.30 & $23^{\circ} \mathrm{c}$ & $85 . \%$ & 469 \\
\hline & 12.30 & $42^{\circ} \mathrm{c}$ & $26 . \%$ & 290 \\
\hline & 17.30 & $30^{\circ} \mathrm{c}$ & $75 . \%$ & 490 \\
\hline Jumat & 07.30 & $26^{\circ} \mathrm{c}$ & $81 . \%$ & 552 \\
\hline & 12.30 & $37^{\circ} \mathrm{c}$ & $28 . \%$ & 380 \\
\hline & 17.30 & $25^{\circ} \mathrm{c}$ & $78 . \%$ & 500 \\
\hline Sabtu & 07.30 & $20^{\circ} \mathrm{c}$ & $95 . \%$ & 475 \\
\hline & 12.30 & $45^{\circ} \mathrm{c}$ & $28 . \%$ & 380 \\
\hline & 17.30 & $25^{\circ} \mathrm{c}$ & $83 . \%$ & 440 \\
\hline Minggu & 07.30 & $22^{\circ} \mathrm{c}$ & $88 . \%$ & 470 \\
\hline & 12.30 & $43^{\circ} \mathrm{c}$ & $28 . \%$ & 399 \\
\hline & 17.30 & $25^{\circ} \mathrm{c}$ & $83 . \%$ & 470 \\
\hline & & & & \\
\hline
\end{tabular}
dari penelitian pada greenhouse yang dilakukan selama satu minggu setiap harinya pemantauan suhu dan kelembaban tanah serta udara dilakukan satu hari tiga kali jam 07.30, 12.30, dan 17.30 pada penelitian tersebut didapat suhu udara mulai tinggi pada jam 12.30 dan kelembapan udara mulai mengalami penurunan pada jam 12. 30 .

\subsection{Hasil Perubahan Kelembaban Udara,Suhu Dan Kelembaban Tanah Secara Otomatis}

Tabel 2 suhu dan kelembaban akhir 


\begin{tabular}{|c|r|c|c|c|}
\hline HARI & JAM & Suhu & Kelembaban udara & Kelembaban tanah \\
\hline Senin & 07.30 & $30^{\circ} \mathrm{c}$ & $83.0 \%$ & 500 \\
\hline & 12.30 & $30^{\circ} \mathrm{c}$ & $83.0 \%$ & 500 \\
\hline & 17.30 & $30^{\circ} \mathrm{c}$ & $83.0 \%$ & 500 \\
\hline Selasa & 07.30 & $30^{\circ} \mathrm{c}$ & $83.0 \%$ & 500 \\
\hline & 12.30 & $30^{\circ} \mathrm{c}$ & $83.0 \%$ & 500 \\
\hline & 17.30 & $30^{\circ} \mathrm{c}$ & $83.0 \%$ & 500 \\
\hline Rabo & 07.30 & $30^{\circ} \mathrm{c}$ & $83.0 \%$ & 500 \\
\hline & 12.30 & $30^{\circ} \mathrm{c}$ & $83.0 \%$ & 500 \\
\hline & 17.30 & $30^{\circ} \mathrm{c}$ & $83.0 \%$ & 500 \\
\hline Kamis & 07.30 & $30^{\circ} \mathrm{c}$ & $83.0 \%$ & 500 \\
\hline & 12.30 & $30^{\circ} \mathrm{c}$ & $83.0 \%$ & 500 \\
\hline & 17.30 & $30^{\circ} \mathrm{c}$ & $83.0 \%$ & 500 \\
\hline Jumat & 07.30 & $30^{\circ} \mathrm{c}$ & $83.0 \%$ & 500 \\
\hline & 12.30 & $30^{\circ} \mathrm{c}$ & $83.0 \%$ & 500 \\
\hline & 17.30 & $30^{\circ} \mathrm{c}$ & $83.0 \%$ & 500 \\
\hline Sabtu & 07.30 & $30^{\circ} \mathrm{c}$ & $83.0 \%$ & 500 \\
\hline & 12.30 & $30^{\circ} \mathrm{c}$ & $83.0 \%$ & 500 \\
\hline & 17.30 & $30^{\circ} \mathrm{c}$ & $83.0 \%$ & 500 \\
\hline Minggu & 07.30 & $30^{\circ} \mathrm{c}$ & $83.0 \%$ & 500 \\
\hline & 12.30 & $30^{\circ} \mathrm{c}$ & $83.0 \%$ & 500 \\
\hline & 17.30 & $30^{\circ} \mathrm{c}$ & $83.0 \%$ & 500 \\
\hline & & & & \\
\hline
\end{tabular}

Tabel diatas merupakan hasil pengujian alat otomatis pada ruangan greenhouse dengan hasil nilai yang kembali normal. Pengujian tersebut di lakukan selama tuju hari dan satu hari tiga kali penyiraman pada jam 07.3012 .3017 .30 dengan hasil nilai kembali nornal didalam greenhouse tersebut

\subsection{Hasil Percobaan Pada Budidaya Tanaman Sawi}

Tabel 3. Hasil percobaan budidaya tanaman sawi

\begin{tabular}{|l|l|c|c|c|l|}
\hline NO & GAMBAR & SUHU & $\begin{array}{c}\text { Kelembaban } \\
\text { Udara }\end{array}$ & $\begin{array}{c}\text { Kelembaban } \\
\text { Tanah }\end{array}$ & Keterangan \\
\hline 1 & & $\begin{array}{c}\text { Suhu } \\
<\end{array}$ & & - & $\begin{array}{l}\text { Tanaman sawi tumbuh } \\
\text { dengan baik dan subur } \\
\text { pada suhu udara } \\
\text { tersebut. }\end{array}$ \\
\hline 2 & $30 \mathrm{c}$ & - & - & $\begin{array}{l}\text { suhu yang tinggi } \\
\text { sawi menjadi layu } \\
\text { karena terlalu panas } \\
\text { mengakibatkan } \\
\text { tangkai layu dan } \\
\text { daun kering. }\end{array}$ \\
\hline
\end{tabular}




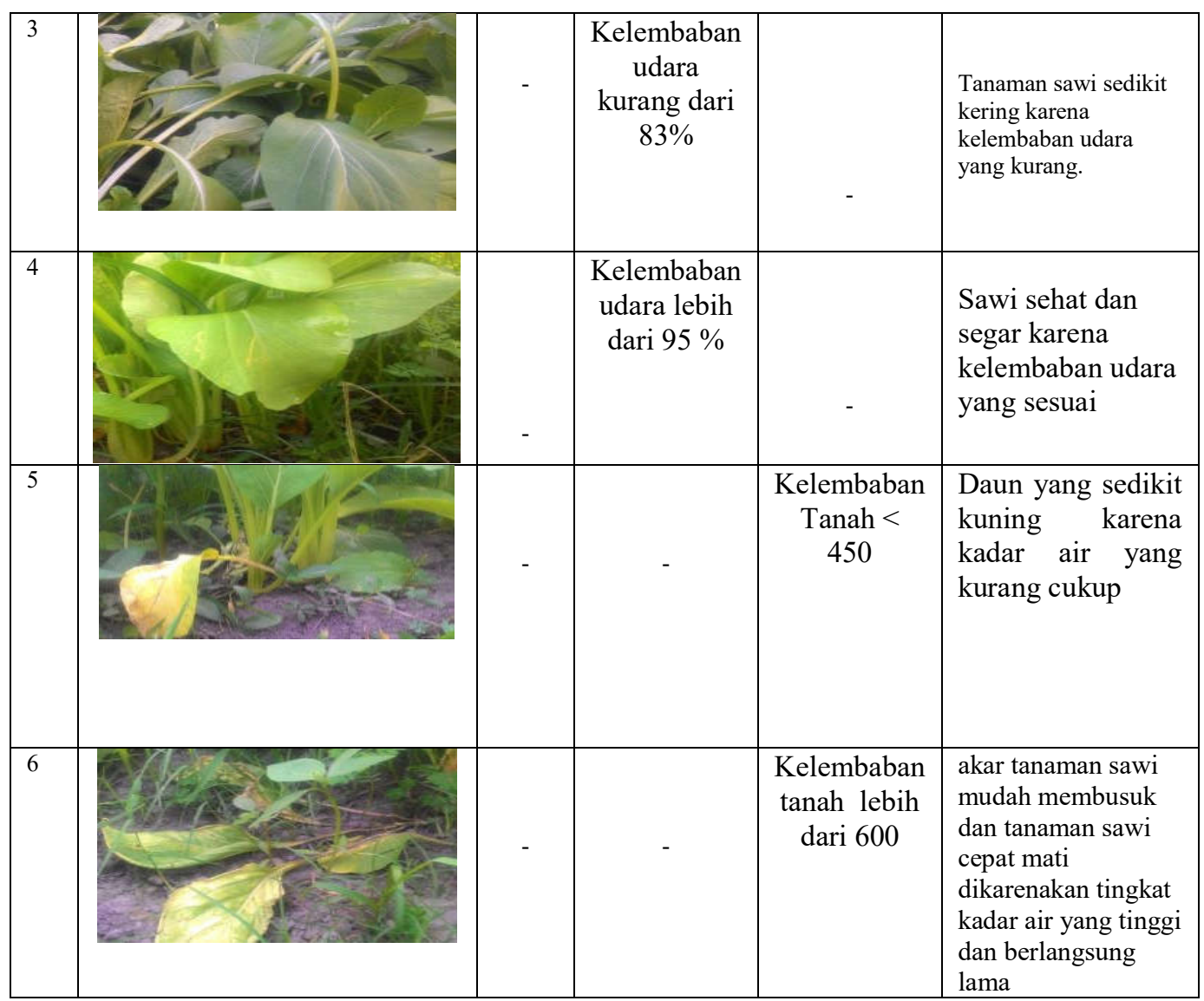

5.

\section{KESIMPULAN}

Dalam penelitian ini masalah pembacaan kondisi suhu udara dan kelembaban tanah pada greenhouse dapat diselesaikan dengan menggunakan sensor DHT11 dan Soil Moisture YL-100 penggunaan sensor tersebut dapat membaca kondisi pada ruangan greenhouse dan dapat membaca tingkat kadar air didalam greenhouse yang sedang digunakan untuk budidaya tanaman sawi. Dalam pengendalian suhu udara dan kelembaban tanah yang otomatis dan dapat dipantau hasil nilai dari kedua sensor menggunakan server yaitu dengan cara menambahkan kode $<30$ dan $>83$ pada Arduino IDE penggunaan chip ESP8266 yang terhubung pada Arduino Uno akan mengirim data melalui jaringan internet yang terhubung dengan server.

\section{SARAN}

Perancangan alat ini mempunyai sedikit kekurangan pada monitoring melalui server ketika jaringan wi-fi sedang ada masalah penggunakan LCD pada tahap penelitian selanjut akan membantu memantau tingkat nilai pada media greenhouse disaat jaringan ada masalah. dalam pembacaan sensor tanah juga dialami pada sedikit kekurangan pada pembacaan sensor yang terbali dan akan diperbaru pada penelitian selanjutnya dengan menggunakan sensor Soil Moisture YL-39 atau YL69

\section{DAFTAR PUSTAKA}

[1] https://id.m.wikipedia.org/wiki/Rumah kaca

[2] Rukmana (2002) Tanaman Sawi Hijau

[3] Cahyono (2003). Klasifikasi Tanaman Caisin 
[4] Sitrusta Sukaridhoto, ST.Ph.D (2016) Bermain Dengan Internet Of Things Dan BigData, Politeknik Elektronika Negeri Surabaya

[5] Herry Yuliansyah (2016) Uji Kinerja Pengiriman Data Secara Wireless Menggunakan Modul ESP8266 Berbasis Rest Architecture, Teknik Elektro, Institut Teknologi Sumatera

[6] Abdul Kadir, "From Zero To A Pro Arduino",2015.

[7] Taufik Z, “Penjelasan Dan Cara Kerja Konsep Internet Of Things”,2017. 